\title{
The relevance of images in user-generated content: a mixed method study of when, and why, major brands retweet
}

\section{Kardi Somerfield* and Kathleen Mortimer}

Faculty of Business and Law, University of Northampton, Northampton NN2 7AL, UK

Email: Kardi.Somerfield@northampton.ac.uk Email: kathleen.mortimer@northampton.ac.uk *Corresponding author

\section{Geraint Evans}

\author{
62 The Avenue, \\ London, NW6 7NP, UK \\ Email: info@drgoevans.com
}

\begin{abstract}
This paper develops unique new insight for business practitioners and academic researchers into the interaction between consumers and brands on social media platforms, principally where brands choose to interact with, and amplify, user-generated content (UGC) by retweeting it on their own brand channels. Despite increasing research into social media in general, there is a relative lack of available academic research on major brands engaging with consumer content, which may, be in part due to the pace of change and exponential growth in this emerging area. This mixed method study develops insight conducted over an 18-month period with leading social media practitioners, concluding that primarily a brand's social media team opportunistically seek out and retweet organic image-led UGC to convey specific messages across multiple platforms. Content containing imagery lends authenticity to brand storytelling; brands with tangible products are more likely to receive organic UGC which contains images than intangible brands.
\end{abstract}

Keywords: social media; branded content; community management; usergenerated content; UGC; images; engagement; retweet; platform; Twitter; Facebook; Instagram.

Reference to this paper should be made as follows: Somerfield, K., Mortimer, K. and Evans, G. (2018) 'The relevance of images in user-generated content: a mixed method study of when, and why, major brands retweet', Int. J. Internet Marketing and Advertising, Vol. 12, No. 4, pp.340-357.

Biographical notes: Kardi Somerfield is a Senior Lecturer, Field of Marketing \& Entrepreneurship and Program Leader, BA Advertising \& Digital Marketing, at the Faculty of Business and Law at the University of Northampton, UK. Her research interests include international marketing, advertising, marketing communications, consumer behaviour, digital \& social media. 
Kathleen Mortimer is an Associate Professor in Marketing Communications, at the Faculty of Business and Law at the University of Northampton UK. Her research interests include international marketing, advertising, marketing communications, consumer behaviour, digital \& social media.

Geraint Evans is Marketing Practitioner \& Researcher. His research interests include international marketing, advertising, marketing communications, consumer behaviour, digital \& social media.

\section{Introduction}

Consumers increasingly talk about companies and products on Social Media with positive sentiments. Many companies have realised the value of this naturally occurring endorsement and now routinely harvest and republish user-generated content (UGC) which has been created by their advocates. How do they decide which content to use?

Interviews with five social media practitioners followed by analysis of the Twitter feeds of seven UK consumer brands for 18 months found that the most significant factor was the inclusion of the company's Twitter handle ‘@Company' closely followed by the presence of a suitable image. Social Media Managers are predisposed to syndicate posts containing imagery and these posts go on to produce more engagement than posts which do not. Businesses increasingly see social media as a central route for marketing communications. Success in social media requires not only for the appropriate networks to be identified but for appropriate tools and strategies to be applied (Halligan and Shah, 2009 ). Around $63 \%$ of adults participate in the social networking site belonging to a brand, and 76\% shop online (Nielsen, 2014). These consumers talk about brands and products on and off line, which has a significant influence on prospective customers.

The power of this electronic word-of-mouth is not limited to the online environment - online opinion impacts on offline attitudes (Smith, 2009). To utilise social media platforms effectively for marketing communications, we have to recognise that socialising online is all about participation in discussions and sharing of ideas and content (Chaffey and Ellis-Chadwick, 2012). If we agree that sharing content is significant in the relationship between a brand and its audiences, then understanding the nature of content which is most likely to be created and shared is important. Numerous brands have realised the power of this organic user-generated content and are harnessing and promoting it as part of their content strategy, both on the social media platforms where it occurs and in some cases beyond, into their mainstream advertising. But which content do they select to share?

This study considers the nature of the content most often shared by brands, with specific reference to imagery. Social media platforms which lead with imagery as their primary form of UGC - such as Instagram, Pinterest and Snapchat - are on the rise. Image capturing, editing and sharing is proliferating, enabled by mobile phone technology and availability. 


\section{Review of social media literature domains}

The area of social media research has increasingly been focused on by academic researchers. Several literature domains have emerged focused on well-being (Burke and Kraut, 2017) and perception of body image (Ghaznavi and Taylor, 2015; Fardouly and Vartanian, 2016) attracting several pieces of research and academic writing on the more negative influences of such social interaction; examination of brand-led production of bespoke content for specific social media platforms (Geissinger and Laurell, 2016), consumer attitude and purchasing behaviour (Prentice and Handsjuk, 2016) and also the phenomena of 'virality' in social media content (Blommaert and Varis, 2017).

There is, however, a relative paucity of recent academic research on major brands engaging with consumer produced content (User-Generated Content), and in particular image led production of content by consumers themselves (as opposed to production by a brand). This may be in part due to the pace of change and exponential growth in this emerging area developing multiple new areas of academic enquiry, but also is potentially due to a focus on research on how consumers interact with brand produced social content, rather than their motivations behind the exponential growth in production of original content themselves, that can then, in turn, be harnessed by brands seeking to appear authentic and engaged with their end-customers on digital platforms through recognition or 'retweeting' of the content, and amplifying of it. As such, this research seeks to address some of these gaps in the available literature through analysis of relevant academic writing before summarising original research in this area with practitioners and proposing additional areas for research.

\subsection{User-generated content}

User-generated content is a primary means by which consumers express themselves and communicate with others (friends or other users not known to them but using the same social media platform) in contemporary society (Boyd and Ellison, 2008). UGC which mentions a brand is generally thought to be of high value to the company concerned (assuming it is positive in nature) due to the attribute of authenticity which in turn creates 'social proof' (Chaffey, 2014; Sabate et al., 2014). Social proof is a term originally developed in the field of psychology, synonymous with 'informational social influence', to describe the phenomenon whereby people faced with a situation where they don't know what to do, look to those around them for cues on how to behave. This term is now commonly used by digital marketing practitioners to describe how consumers look to other consumers to inform their actions (Cheong and Morrison, 2008). Marketers are particularly interested in this in a consumer buyer behaviour context.

Authenticity is another term often used in conjunction with UGC. Brands seek to be transparent, honest and trustworthy in a bid to build customer relationships. At its best, genuine comment by a real user can be incredibly powerful and 'authentic'. In particular, the concept that the content creator has no commercial vested interest is pivotal in developing trust (Litvin et al., 2008). Studies into how credible consumers find usergenerated posts to be, found that the subjects of their study trusted product information which was created by consumers more than information generated by manufacturers this was true for both positive and negative content (Cheong and Morrision, 2008; Liu et al., 2011). This supported an earlier study which found that prospects prized information generated by consumers more highly than advertising (Goldsmith and Horowitz, 2006). 


\subsection{Motivation to create branded content}

On Twitter in particular, users seem highly aware of the public nature of their posting, and that their posts reflect on them personally or at least their online persona in that forum (Araujo et al., 2015). So what motivates consumers to post? Functional theory is generally considered to be fundamental to understanding motivation and behaviour (Katz, 1960). Theory in this area describes four personality functions; utilitarian, knowledge, ego-defensive and value-expressive.

All four of these motivations would require different stimulus and result in a different outcome in relation to UGC. The utilitarian type revolves around self-interest - gaining a reward. The knowledge function relates to the individual's need to acquire information to organise and understand their environment or themselves - the acquisition of wisdom. The ego-defensive type is involved with creating content to minimise self-doubt, create a sense of belonging or even to assuage a sense of guilt if they do not create content. The value expressive type involves creating content which expresses self-concepts, creating a sense of self-esteem and gratification at involvement with a community which they hold to be important (Daugherty et al., 2008).

\subsection{Marketers as a syndication route for user-generated-content}

The promoting and repurposing of UGC by marketers has been termed 'user-generated branding' (UGB) (Burmann, 2010). Earlier descriptions of 'vigilante marketing' and the idea of the 'prosumer' did not go far enough in describing these user-generated brand messages which were proliferating. Further, a useful distinction was made between sponsored $U G B$ which was prompted and rewarded by recognition or in monetary terms, and non-sponsored $U G B$ - the naturally occurring but free-form advocacy (Burmann, 2010). Although the term UGB is proposed, the author has not adopted UGB in the place of UGC for this study for two reasons; the term does not seem to have developed into common usage by practitioners, and the emphasis on branding seems misplaced - in the context it is being used here, content is clearly central.

By 2014 practitioners have certainly begun to leverage the assets generated by users with images and videos being repurposed by some very big consumer brands including Domino's Pizza, M\&Ms, Oreos, Starbucks and GoPro (Marrs, 2014). Typical techniques are the harvesting and reposting (sometimes adapted version) of user photographs.

\subsection{The relationship between images and pass-along behaviour}

The academic literature contained studies which analysed social media content virality in the context of consumers' actions. No studies were identified that related to the syndication of UGC by brands. The two most salient models identified - the SPIN framework (Mills, 2012) and Kantar's REACH framework (Burke and Mackay, 2014), discuss a range of factors, but form is not one of them. SPIN does mention 'content richness' of which image is a part, similarly images are part of the 'information' examined in the study by Araujo et al. (2015). On Twitter, consumers prefer to pass along brand messages when they are information-rich, which include product details, web links, photos and videos (Araujo et al., 2015). This underlines the necessity of creating rich content if a brand seeks to extend the reach of its posts by onward transmission by social media followers. 
Practitioners and authors in the digital marketing field sometimes talk about the ' $3 \mathrm{x}$ Rule' of digital marketing; that is, that posts with images are three times more likely to be liked or shared than those without. On Facebook for example it was found that images receive $22 \%$ more engagement than video posts and $54 \%$ more than text posts, but videos receive $27 \%$ more engagement than text posts (Brookes, 2010). In a more recent study, richness of content - the inclusion of images and video - increased the number of likes, while the time of day was the main predictor of the number of comments (Sabate et al., 2014). Out of a range of factors, the inclusion of images in posts seemed to create the greatest engagement (likes and comments) on Facebook fan pages in the tourism sector (Smith et al., 2012). It was observed that pictures take only a few seconds to digest whereas video requires a greater investment of time

Kantar Media included research into imagery as part of a wider investigation into 'Creating Contagious Content' on social media (Burke and Mackay, 2014). They found a correlation between the response to the question 'To what extent do you agree with the statement "It's got good pictures"?' and a stated likelihood that the subject would share the content (or already had). They found that where a picture was rated 5 or more on a 7 point Likert Scale, it begins to affect the propensity to share the post. They further found that this was not a perfect correlation, and that posts without pictures would still sometimes be shared. So images seem to be significant in pass along behaviour with the content originated by brands; this research sought to find out whether the same was true of content originated by users.

\subsection{Images in social media}

Images have always been a key component of identity for humans - but changes to society and technology have meant that images now perform a new and highly significant role in identity formation - images shared on social media are now the primary vehicle for the sharing of tastes and experiences, pointing to the global currency and depth of meanings and associations they permit (Pulman-Jones and Strong, 2013).

The ubiquity of pictures made available by technology has resulted in the development of a vocabulary of images similar to writing (Scott and Vargas, 2007). There is a widespread ability to read pictures and advertisers have an increasing preference for figurative content (Phillips and McQuarrie, 2002). While this would seem to be something new - facilitated by the internet - actually communication with images predates what we think of now as writing. Modern methods of writing involve processing ideas into spoken language first and then capturing it - often phonetically. In contrast, most of the writing of early cultures had a largely pictorial content.

\section{Research design and methodology}

\subsection{Research questions}

- What are the characteristics of the UGC brands are Retweeting?

- What factors do Social Media Managers consider when choosing which UGC to syndicate?

- Does the presence of an image impact the performance of UGC? 
The research strategy adopted was a mixed methodology consisting of pre-test practitioner interviews and a pilot for the quantitative study, followed by the observational analysis of Twitter accounts.

\subsection{Practitioner interviews}

The first phase of the research was a series of semi-structured interviews with industry practitioners. The population of interest for the qualitative study was: marketing professionals who work primarily with social media accounts for consumer-facing organisations. Five participants were recruited; their job titles were Social Media Manager, Digital Engagement Manager and Communications Officer (Social Media and Online Communities). Questions were developed on the basis of the findings of the literature review and the proposed design of the quantitative study. The main areas in the topic guide were:

- Subject classification (responsibility, autonomy, experience, decision making).

- Social media strategy (priorities, targets, measurement).

- Content strategy (source of content, UGC).

- UGC selection (sentiment, brand centricity, image, relevance, followers).

- UGC promotion and usage (incentives, syndication through other channels, sponsorship, performance).

- Imagery (proportion of posts, effect on performance, beliefs about importance).

The interviews were recorded and transcribed, and then a coding frame developed to enable the cross-referencing of emerging themes in the interviews.

\subsection{Analysis of Twitter feeds}

Following the practitioner interviews there were two elements of data collection and analysis, both of which involved the methodical logging, classification and analysis of content and behaviours on Twitter. Since these behaviours occurred online, they were already captured within the social media environment in which they occurred. Examples of this methodology applied to a social media context include 'What Motivates Consumers to Retweet Brand Content?' (Araujo et al., 2015) 'Has Mumsnet changed me? SNS influence on identity adaptation and consumption' (Phillips and Broderick, 2014) and 'Observation on copying and pasting behaviour during the Tohoku earthquake: Retweet pattern changes' (Kim, 2014). The phenomenon of interest for the quantitative study was: content which was created by a private individual and then reused by a company for promotional purposes. Seven brands were identified and their social media output analysed for evidence of user-generated content. Brands were considered who met the following criteria:

- Brands identified in the IAB's 2015 survey 'Best at Social Media Marketing' (Campaign, 2015).

- Brands reported in the trade press as having an active strategy of using UGC in their social media.

- A variation between tangible/intangible and on/off-line products and services. 
The brands selected were Coca Cola, Nike, Amazon, Starbucks, Three, Pets at Home and Graze. In each case the UK Twitter account was analysed. Twitter was selected as the social media platform to use in the study for two reasons; firstly it is more outwardly facing than Facebook. It is a common convention on Twitter for users to 'tag' a company they are talking about by including the company's username in the Tweet. The mention is a way of ensuring those managing the brand's Twitter feed will see the Tweet; secondly, Twitter is the most neutral in terms of structural content bias. Other platforms such as Pinterest, Instagram, YouTube and Vine all require either an image or video in their posts. Twitter has other restrictions such as a character and picture limit but it does not inherently favour one type of content over another.

Query 1: Comparative analysis of posts 'retweeted' vs. 'not retweeted' by a brand

220 cases of UGC which were not retweeted were compared to 217 cases which were retweeted. Their characteristics across 15 data variables were captured in SPSS.

Query 2: Characteristics of UCG retweeted by seven consumer brands

The accounts in the study was analysed for a period of 12 months (collectively 33,123 posts). Tweets were classified as UGC if they had been created by a consumer and then retweeted by the brand. The quantity of data collected was:

- @AmazonUK 123 cases*

- @CocaCola_GB 27 cases

- @Grazedotcom 139 cases

- @NikeUK 0 cases

- @PetsatHome 200 cases **

- @StarbucksUK 144 cases

- @ThreeUK 142 cases

*22 weeks of data available for Amazon.

**Time horizon restricted to 2 months due to the high volume of UGC (potential to cause a skew in the data).

A total of 704 cases were captured. The data reduction stage involved the classifying each post using 22 data points under the five broad categories of Metadata, Content Richness, Brand Centrality, Advocacy and Content Creator. These categories were derived from the desk research insofar as they were the key themes which emerged during the literature review and the pre-test interviews. The data points had a combination of dichotomous, free text, date, numeric and Likert scale measures (see Figure 1). Each case was saved to a Pinterest board. The application of the classification framework to a Tweet is illustrated in Figure 2. 
Figure 1 Mapping of classification data points

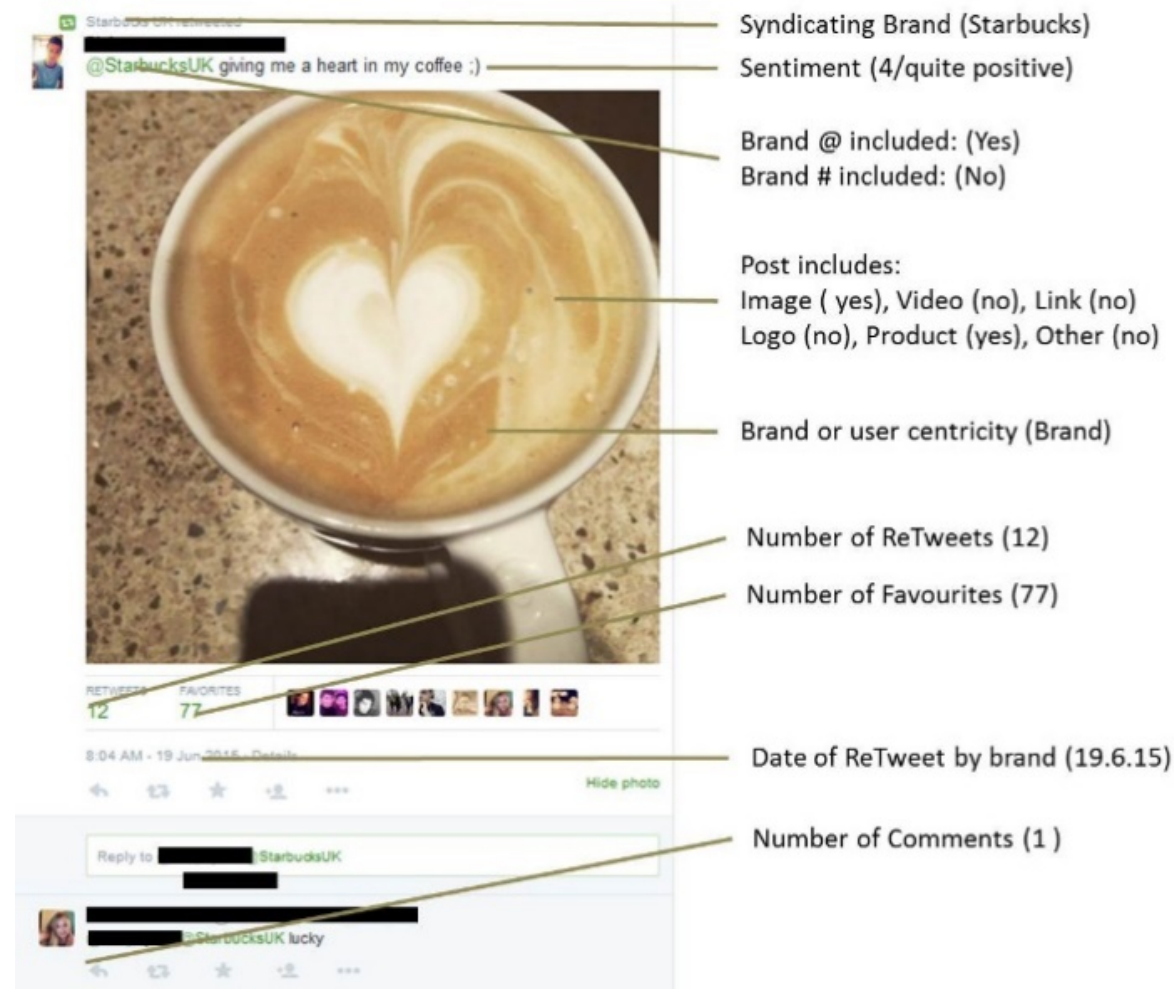

\section{Results and findings}

\subsection{Results of practitioner interviews}

The five subjects are anonymised for the purposes of the study. In each case they have sole responsibility for the social media accounts for their organisations. Two of them also outsource some of the customer service activity to an external vendor. Both of these companies are retailers and experience a high volume of service type queries on Twitter.

All of the interviewees are the first dedicated Social Media Managers in their respective companies, the roles having been created within the last 2 years in each instance. There was a range of experience level from significant experience working in Social Media at a previous large brand, to an early-career marketer in their first full time job. In each case they have a high level of autonomy in their role and largely make the decisions in terms of the social media strategy while acting as part of the wider Marketing Department.

\subsection{Content sources}

A high proportion of the content for the accounts of Subject 2 and 4 originated from their press teams or and internal departments. Subject 1 in contrast spent a lot of her time 
working with external partners - typically manufacturing. Subject 3's Twitter feed was more UGC led. A larger proportion of the content comes from users, and even the company-authored Tweets are illustrated with UGC-sourced images. Some of the other content is from 3rd party charity partners and subject matter experts. They felt that this would change in the near future however, in a statement similar to Subject 1's above, said "I imagine pretty much every marketer you will have spoken to will say this; you've got to be in content. It's a journey that our company are certainly on at the moment." Subject 5, a clothing brand said that most of their content was product photography-led and generated by their creative agency. All participants described how they overlay a number of calendars to plan their content. This included seasonal events and the marketing calendar with events such as sales and product launches, but some of it was responsive to external factors such as getting involved in a meme that was trending (a humorous image/text which circulates in social media with slight variations). Three of the five subjects made unprompted mention of the need to use rich content, for example "What we try to do is use a lot more engaging media so a lot more video vines, Instagram videos, pictures from professional photographers which seems to have a really positive impact". Subject 2 and 3 also discuss the need to evoke emotions - "Twitter is quite an emotional platform. Emotions are key - you'll see trends on how people are feeling. I think the more you invoke an emotional response from the people that read that Tweet, the more interaction you get as well."

\subsection{User-generated content and syndication}

There was a wide variation of the extent to which the brands promoted UGC as part of their content strategy. Subject 3's company is by far the heaviest adopter of UGC, using it to put consumers at the heart of their business: "You probably know that all of our TV was sourced throughout social media channels.... One thing that we find with our social community is that they are so engaged it gives us a really good insight into what they enjoy - so how we can start to use that to influence content, product development and that kind of thing." He goes on to say "All the memes that we do are using genuine pictures submitted by customers. We've been doing that for the last 18 months. In fact I'm looking down our wall now and pretty much all of the pictures on there are usergenerated.... I can't actually see one yet that's a stock shot."

Subject 2 has also put UGC at the heart of the social media storytelling strategy; "To improve my advocacy score I've been trying to make my page much more personal to the people on it. That's part of the proposition on the Facebook page" she says.

Subject 3 pointed out the importance of both Facebook and Twitter as a source of brand storytelling - whereby events originating in-store could be followed and developed into assets to use across platforms. Subject 2 explained how customer stories were developed in long form for the Facebook page but short form for Twitter, and often she used Instagram to improve the consumer's pictures. Subject 3's company also have a practice of repurposing stories across channels: "Oh yes we flip the two quite a lot, in fact one of the things we've put on Instagram today a lady shared on our Facebook page - it's not actually on Twitter yet but, yes we do syndicate between them. But what's quite nice is we syndicate them outside of social as well."

Subject 5 in contrast used barely any UGC. "We are trying to reposition the brand and also, with our 50-70 age demographic we just don't get the kind of UGC that is styled in a way that supports the look we want. We do get pictures of people wearing our products...it's just not stuff we can use." 


\subsection{Decision to retweet}

The primary reason not to retweet UGC with positive sentiment was poor spelling and grammar. "Spelling and grammar is probably the most important thing - if anything is spelled wrong I just won't retweet it." says Subject 1. All participants discussed this without prompting. Similarly, the use of profanity in the Tweet or even in the username was problematic explains Subject 2:" Sometimes there have been great mentions of us but the person posting has had a really bad Twitter handle - like with bad swearwords in it - I can't use that. Even the C word". Another reason to reject material to retweet was the avoidance of controversy or politics. Positive reasons to retweet were anything featuring selfies (photographs) using the product or service (Subject 4, Subject 3, Subject 1) "We'd be all over that" says Subject 4. All subjects discussed the need for the content to be of interest to the audience - positive mention of their brand was not enough to warrant syndication.

\subsection{The importance of images}

All of the subjects held the belief that posts including images gained more engagement than those without. When questioned about the source of the belief, some cited training (Subject 1, Subject 3). All claimed to have observed it in their analytics although estimates of how much impact including an image had differed widely. Subject 2 believed it was common sense.

"We tend to retweet if it has a picture or a link in it - just because there's more to it, so it's much more likely to be sequentially picked up by other people... Certainly in our proactive approach, we will do anything we can to ensure there's some sort of media in there. It's very rare that we would put anything out that did not have an image in it."

Figure 2 Factors in the decision to retweet UGC (thematic coding of interviews)

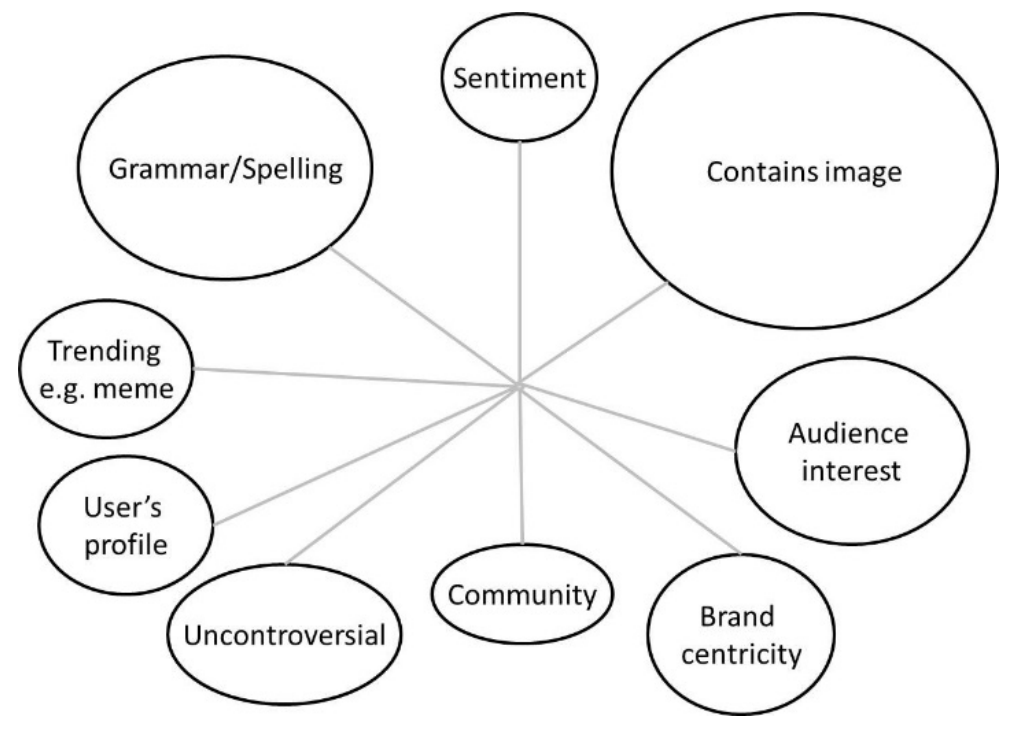


When discussing the quality of images arising from UGC there was a difference of opinion. Subject 1 maintained she wanted a 'squeaky clean timeline' and would reject a poor image that was not on brand or one that had been 'enhanced' with hearts and crowns in an app. Subject 3 disagreed - believing that over-professional images seemed less authentic and were therefore less desirable.

The main themes mentioned when discussing UGC are illustrated in Figure 2.

The brands being studied have quite a difference in the scale of their audiences, and the level of activity on Twitter are illustrated in Table 1.

Table 1 Analysis of posting frequencies

\begin{tabular}{lccc}
\hline & Followers & Average tweets per day & \% of UGC \\
\hline Amazon & $1,695,550$ & 6.35 & $5.00 \%$ \\
Coca Cola & 127,949 & 16.15 & $0.46 \%$ \\
Graze & 65,997 & 33.30 & $1.15 \%$ \\
Nike & 383,156 & 12.95 & $0.00 \%$ \\
Pets at Home & 49,763 & 13.90 & $24.42 \%$ \\
Starbucks & 674,786 & 11.16 & $3.53 \%$ \\
Three & 134,889 & 13.52 & $2.87 \%$ \\
\hline
\end{tabular}

Amazon has the biggest audience but the lowest volume of Tweets. Graze publishes the most Tweets - twice as many as their closest rival on this list, while Pets at Home is the biggest user of UGC by a very wide margin.

\subsection{Characteristics of retweeted vs. un-retweeted UGC-CHAID analysis}

This section refers to the analysis of Tweets which were user-generated and referred to the company Pets at Home in their content. A Chi Square Automatic Interaction Detection (CHAID) analysis was undertaken to determine which of the independent variables were most significant in creating the outcome 'Retweeted by Pets at Home'.

The primary significant variable was the presence of the brand's handle @PetsatHome. Of the 217 cases of retweeted content, only one did not contain the @ PetsatHome handle. The only other significant variable was the presence of an image. $79 \%$ of the retweeted posts contained an image whereas the percentage of inbound UGC with an image was $31 \%$.

Table 2 Classification of UGC-CHAID analysis

\begin{tabular}{lccc}
\hline \multirow{2}{*}{ Observed } & \multicolumn{3}{c}{ Predicted } \\
\cline { 2 - 4 } & YES & NO & Percent Correct \\
\hline YES & 176 & 41 & $81.1 \%$ \\
NO & 46 & 174 & $79.1 \%$ \\
Overall Percentage & $50.8 \%$ & $49.2 \%$ & $80.1 \%$ \\
\hline
\end{tabular}

Note: Growing Method: CHAID; Dependent Variable: Retweeted by PAH. 
Figure 3 Characteristics of UGC-CHAID analysis

Retweeted by PAH

\begin{tabular}{|l|lr|}
\hline \multicolumn{3}{|c|}{ Node 0 } \\
Categony & $\%$ & $n$ \\
\hline YES & 49.7 & 217 \\
NO & 50.3 & 220 \\
\hline Total & \multicolumn{1}{|c|}{100.0} & 437 \\
\hline & \multicolumn{2}{|c|}{} \\
\hline
\end{tabular}

Contains (QPetsatHome Adj. P-value $=0.000$, Chisquare $=157.739, \mathrm{~d}=1$

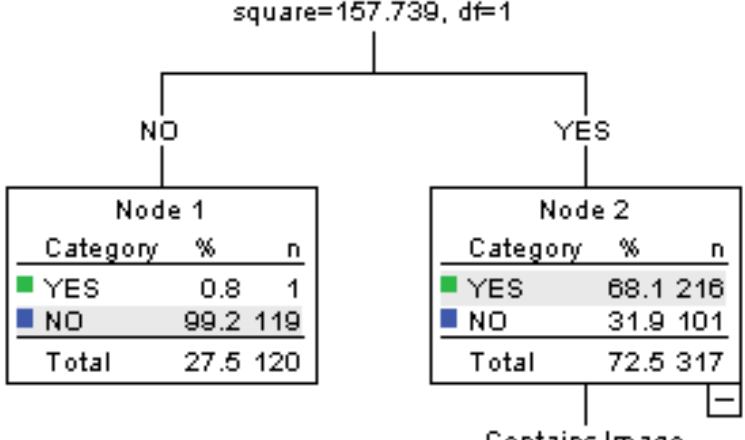

Adj. P-value $=0.000$, Chi-square $=42$.

349, $d f=1$

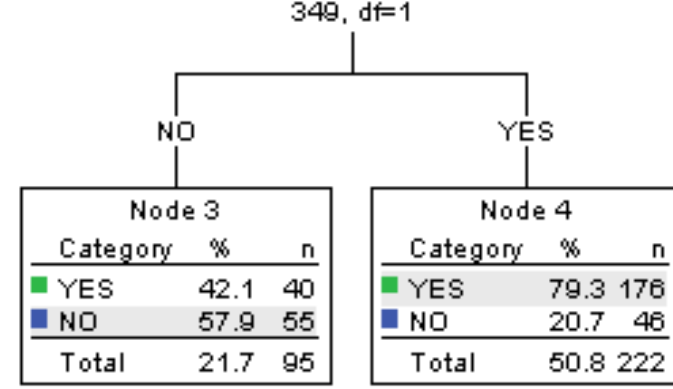

\begin{tabular}{|c|c|}
\hline \multicolumn{2}{|c|}{ Risk } \\
\hline Estimate & Std. Error \\
\hline .199 & .019 \\
\hline
\end{tabular}

Note: Growing Method: CHAID; Dependent Variable: Retweeted by PAH.

\subsection{Proportion of image to text and other in syndicated UGC}

This section refers to content analysis of the Tweets which were user-generated, and which were reposted (syndicated) by the brands being studied, during the first six months of 2015 . Across the whole data set, only one case did not contain text (a picture with no text). $71 \%$ of the posts contained an image, together with text. At a brand level, however, there was more variation with half of Three's UGC posts containing an image while Starbucks and Graze had $75 \%$ and $79 \%$ respectively. Three incidences of video were 
observed in the data, one for Starbucks and two for Graze. There were 9 cases of posts which included an external link in the data. These were links to blogs or accounts on other social media platforms e.g. Instagram.

\subsection{Brand centricity of images}

126 of the cases contained an image. Each case was evaluated for brand- or usercentricity, which was the estimation of whether the post was most focused on the brand, the user or neutral. $72 \%$ were brand-centric, while $21 \%$ were neutral. Only $6 \%$ were usercentric. Of the UGC retweeted by Three, $89 \%$ of them were brand-centric. The posts Starbucks chose to syndicate were $75 \%$ brand-centric but there were more cases of neutrality (14\%) and almost as many which were user-centric. This was somewhat of an anomaly, as four of these were the work of an artist who draws on Starbucks cups, and the focus was more on the artist. The Graze results showed the lowest level of brandcentrality $(60 \%)$, with $38 \%$ where the brand and the user featured to a similar extent (i.e. Neutral). Graze and Three each had only one post which was user-centric. In $76 \%$ of the cases where an image was present, the product was featured in the image $(24 \% \mathrm{did}$ not). Surprisingly, the brand with the highest proportion of images featuring a product was Three - surprising because mobile telephony is a rather intangible product. These cases were re-examined and it was found that in some cases the hardware was photographed, and in others a screenshot an app measuring the performance of the broadband had been posted. Others were photographs taken with a particular model of mobile phone. It was also noted that although the percentage was high, the sample size was small - only 19 cases. Products featured in the UGC pictures for Starbucks in $81 \%$ of cases, and for Graze in $76 \%$ of cases. Each syndicated UCG post with an image was examined for the presence of a logo. Overall a Logo did appear in $56 \%$ of the images. Starbucks posts featured the logo in $68 \%$ of images, usually on the cup in a product shot. Graze featured the logo in $52 \%$ of the cases - again, predominantly on the packaging. Only $26 \%$ of the Three posts included a logo.

\subsection{Image vs. non-image virality - MANOVA analysis}

In order to evaluate the impact of image on post virality, the total number of Favourites and retweets were captured for each branded UGC post. There was no multicollinearity, as assessed by Pearson correlation $(r=.499, p=.000)$. These were then subjected to a one-way MANOVA test (Table 3).

Table 3 One-way MANOVA test

\begin{tabular}{|c|c|c|c|c|}
\hline \multicolumn{5}{|c|}{ Descriptive Statistics } \\
\hline & Does the post contain an image? & Mean & Std. Deviation & $N$ \\
\hline \multirow{3}{*}{$\begin{array}{l}\text { Number of Likes for } \\
\text { the post }\end{array}$} & Yes & 26.62 & 35.584 & 498 \\
\hline & No & 19.44 & 25.932 & 197 \\
\hline & Total & 24.58 & 33.275 & 695 \\
\hline \multirow{3}{*}{$\begin{array}{l}\text { Number of Retweets } \\
\text { for the post }\end{array}$} & Yes & 8.19 & 14.898 & 498 \\
\hline & No & 5.15 & 6.453 & 197 \\
\hline & Total & 7.33 & 13.137 & 695 \\
\hline
\end{tabular}


There was no homogeneity of variance-covariances matrices, as assessed by Box's test of equality of covariance matrices $(p=.000)$, and also there were different sample sizes therefore Pillai's Trace method was used to evaluate statistical significance.

There was a statistically significant difference between the posts which contained images and those which did not on the combined dependent variables, $F(2,692)=4.783$, $p=0.009$; Pillai's $\Lambda=.014$; partial $\eta^{2}=.014$.

Overall it was found that posts with images outperformed those without for the normal measures of social media action. There were however some notable differences between the brands - Amazon with by far the biggest audience had a very low rate of onward sharing. Coca Cola and Amazon both saw their 'no image' posts performing better than the ones with images, while for Three it made no difference. In contrast, for Graze, Pets at Home and Starbucks saw posts with images performing 30-100\% better than those without in terms of likes, while the inclusion of a picture resulted in a $50-300 \%$ uplift in retweets.

Table 4 Response to retweeted UGC posts (mean, per thousand followers)

\begin{tabular}{lccccc}
\hline & \multirow{2}{*}{$\begin{array}{c}\text { Followers } \\
\text { (thousands) }\end{array}$} & \multicolumn{2}{c}{ Image } & \multicolumn{2}{c}{ No Image } \\
\cline { 3 - 6 } & 1696 & Like & $R T$ & Like & $R T$ \\
\hline Amazon & 128 & 0.03 & 0.00 & 0.06 & 0.00 \\
Coca Cola & 66 & 0.03 & 0.03 & 0.06 & 0.05 \\
Graze & 50 & 0.14 & 0.03 & 0.07 & 0.01 \\
Pets at Home & 675 & 0.21 & 0.18 & 0.16 & 0.06 \\
Starbucks & 135 & 0.12 & 0.03 & 0.08 & 0.02 \\
Three & & 0.07 & 0.03 & 0.07 & 0.03 \\
\hline
\end{tabular}

\subsection{Content themes}

The UGC posts which contained images were analysed for other post content (in addition to product and logo). The main findings here were that Starbucks and Three both posted a lot of content which related to price promotions - Starbucks' Frappuccino Happy Hour and Three's free data abroad service were the main topics. Graze and Three's users posted content which elaborated on the product in some way whereas Starbucks customers did not. Both Graze and Starbucks retweeted artwork on several occasions, whereby users had drawn on the packaging. Similarly Graze tweeted several examples of customers upcycling their packaging in some way.

\subsection{Image vs. non-image virality}

In order to evaluate the impact of image on post virality, the total number of Favourites, Retweets and Comments was captured for each branded UGC post. The totals were divided by the number of the posts to arrive at the mean value, sorted by posts with and without an image. Overall it was found that posts with images outperformed those without for the normal measures of social media action. 
- Graze's posts were most engaging with Favourites 2.75:1, Retweets 3:1 and Comments 1.5:1

- Three's content was the next most successful: Favourites 1.4:1, Retweets 1.6:1 and Comments 1.71:1

- Starbucks' statistics were: Favourites 1.3:1, Retweets 1.47:1 and Comments 1.2:1.

\section{Conclusion and practitioner perspective}

The study aimed to understand the extent to which images played a part in brands' propensity to utilise and syndicate UGC, and further, whether posts containing images were more viral than those without.

\subsection{Are brands more likely to syndicate pictorial user-generated content than text or are other factors more important?}

The quantitative research was emphatic on this point; $71 \%$ of the cases of UGC syndicated by the brands studied on Twitter did contain an image - but together with text rather than on its own. ThreeUK appeared to have adopted a strategy of Retweeting users with high follower numbers. The content that was syndicated had several themes - which varied by brand as might be expected. For example, Starbucks posts often featured a promotion and the product. Graze and Starbucks had examples of original art created with their packaging by customers. Graze had several examples of upcycling of the packaging. The qualitative research sought to find out why image-based UGC was being reposted in higher volume than text-only. In terms of number of mentions, imagery came out top as a factor in the decision repost a user's content. There was some difference of opinion about the importance of the quality of the image; one subject had a preference for images which were on-brand and would edit them if necessary, another preferred the authenticity gained by using images as supplied. Two of the four brands have adopted a clear strategy of consistently using UGC images across platforms.

Spelling and grammar was the second most mentioned factor, this was most often discussed in the context of 'reasons not to repost'. The next highest factor was audience interest, discussed by all but one of the subjects. The qualities of being brand-centric and uncontroversial were also mentioned by several.

All four of the social media managers interviewed held the belief that including images resulted in higher engagement with a post. When questioned about the source of their beliefs, three of the subjects felt that they had the information either from Twitter or other social media training, but held that they had also seen it reflected in their own analytics. The other subject was operating in an environment with somewhat less measurement and had a more instinctive response to the question.

\subsection{Do pictures make UGC more successful?}

A range of studies at different points of time over the last 5 years and using different social media platforms produced a variety of results. One thing that was consistent, was that content with images does outperform content without images in terms of social media actions. So it was seen that UGC syndicated by brands on Twitter which contained 
an image did outperform text-only posts in the engagement measures of Favourites, Retweets and Comments. The ratio observed ranged from 3:1 to 1.2:1. A wider factor impacting the creation and use of images is the changing social media landscape: growing platforms such as Instagram and Pinterest require the inclusion of an image which somewhat forces the issue. In the context of this study, the changing nature of Twitter to a customer service platform was noted by two of the interviewees. The form of the content alone is not enough of course. This is best summed up by one of the Social Media Managers interviewed: "If the anatomy of a Tweet is good - good graphic, good hashtag - you can increase the response rate by $20-30 \%$. But it's the content - it's about finding good stuff from the sector, and sometimes beyond the sector that matters."

The outcomes of the research clearly demonstrate there is careful curation of consumer generated content by household brands, in particular consideration of UserGenerated Content pictures which are 'on brand' and therefore able to add value to the brand's social media platform. The use of images, and the clear conclusion that they are considered more impactful than purely text based UGC, means that they make a post more likely to be retweeted. The use of user-generated content is a growing phenomenon - something that has emerged primarily through the proliferation of mobile devices, and therefore facilitating what global brands have craved for some time in their branding and communication efforts - content that feels authentic, and takes a brand - or brand message - to a new level through offering a unique, and compelling, perspective of the customer themselves. An exciting area to continue to research as it develops, and one that necessitates deeper academic research, customer insight and contribution to understanding from social media practitioners in business.

\section{Limitations}

The inclusion of a greater sample of brands would increase the validity and findings. Extending the scope of the quantitative study to include the analysis of the inbound communication by consumers would reveal the quantity and modality of UGC available to each brand. This would establish whether the characteristics of retweeted UGC result from the properties of the naturally occurring inbound UGC or are a matter of choice by the Social Media Manager. It was not possible to determine in some cases whether the UGC was genuine - one brand in particular had a number of Tweets which looked as though they may have been paid for/sponsored.

\section{Recommendations for further research}

The conclusions of this paper are some recommendations for further research to develop additional insight in this area:

1 The growth of image creation and sharing, enabled by technology is a social phenomenon worldwide. The work of Scott and Vargas which discussed a new vocabulary of images was published in 2007 and would merit being revisited for the present conditions where images can be proven to produce more engagement on social media then purely text based posts. The exponential growth of video should also be considered in the context of performance. 
2 There was very little academic literature about branded UGC at all. This area of research could be extended by doing primary research with users who are heavy or accomplished producers of branded content to establish which of the motivational factors they identify with. In turn this would provide Social Media Managers with insight into how best to motivate their communities to supply content that can be used.

3 Another area for research would be to investigate Employee Generated Content and compare it with User-Generated Content in the context of integrated marketing communications, including the extent to which it drives greater engagement.

\section{References}

Araujo, T., Neijens, V. and Vliegenthart, R. (2015) 'What motivates consumers to retweet brand content?' Journal of Advertising Research, Vol. 55, No. 3, pp.284-295.

Blommaert, J. and Varis, P. (2017) 'Conviviality and collectives on social media: virality, memes, and new social structures', Multilingual Margins: A journal of Multilingualism from the Periphery, Vol. 2, No. 1, p.31. Available online at: http://www.epubs.ac.za/index.php/ multiling/article/view/50 (accessed on 31 October 2017).

Boyd, D. and Ellison, N. (2008) 'Social network sites: definition, history, and scholarship', Journal of Computer-Mediated Communication, Vol. 13, pp.210-230.

Brookes, E.J. (2010) The anatomy of a Facebook post. Study on post performance by type, day of week, and time of day. Available online at: https://marketingavatar.files.wordpress.com/ 2010/11/the-anatomy-of-a-facebook-post.pdf (accessed on 15 October 2017).

Burke, J. and MacKay, E. (2014) 'Social media: creating contagious content', Advertising Research Foundation, Think Conference 2014, New York.

Burke, M. and Kraut, R.E. (2016) 'The relationship between Facebook use and well-being depends on communication type and tie strength', Journal of Computer-Mediated Communication, Vol. 21, No. 4.

Burmann, C. (2010) 'A call for user-generated branding', Journal of Brand Management, Vol. 18, No. 1, pp.1-4.

Campaign (2015) Coke best at social media marketing, says IAB survey of brands and agencies. Available online at: http://www.campaignlive.co.uk/article/1377100/coke-best-social-mediamarketing-says-iab-survey-brands-agencies (accessed on 15 October 2017).

Chaffey, D. (2014) The Best Tools and Tracking Techniques to Save Time on your Social Syndication. Available online at: http:/www.smartinsights.com/social-media-marketing/ social-media-strategy/tools-tracking-social-syndication/ (accessed on 15 August 2016).

Chaffey, D. and Ellis-Chadwick, F. (2012) Digital Marketing: Strategy, Implementation and Practice, Pearson, Harlow.

Cheong, H. and Morrison, M. (2008) 'Consumers' reliance on product information and recommendations found in UGC', Journal of Interactive Advertising, Vol. 8, No. 2.

Daugherty, T., Eastin, M.S. and Bright, L. (2008) 'Exploring consumer motivations for creating user-generated content', Journal of Interactive Advertising, Vol. 8, No. 2, pp.1-24.

Fardouly, J. and Vartanian, L.R. (2016) 'Social media and body image concerns: current research and future directions', Current Opinion in Psychology, Vol. 9, pp.1-5.

Geissinger, A. and Laurell, C. (2016) 'User engagement in social media - an explorative study of Swedish fashion brands', Journal of Fashion Marketing and Management, Vol. 20, No. 2, pp.177-190.

Ghaznavi, J. and Taylor, L.D. (2015) 'Bones, body parts, and sex appeal: an analysis of \#thinspiration images on popular social media', Body Image, Vol. 14, pp.54-61. 
Goldsmith, R. and Horowitz, D. (2006) 'Measuring motivations for online opinion seeking', Journal of Interactive Advertising, Vol. 6, No. 2, pp.1-16.

Halligan, B. and Shah, D. (2009) Inbound Marketing: Get Found Using Google, Social Media and Blogs, Wiley, London.

Katz, D. (1960) 'The functional approach to the study of attitudes', Public Opinion Quarterly, Vol. 24, pp.27-46.

Kim, T. (2014) 'Observation on copying and pasting behavior during the Tohoku earthquake: retweet pattern changes', International Journal of Information Management, Vol. 34, No. 4, pp.546-555.

Litvin, S.W., Goldsmith, R.E. and Pan, B. (2008) 'Electronic word-of-mouth in hospitality and tourism management', Tourism Management, Vol. 29, pp.458-468.

Liu, B., Karahanna, E. and Watson, R. (2011) 'Unveiling user-generated content: designing websites to best present customer reviews', Business Horizons, Vol. 54, pp.231-240.

Marrs, M. (2014) UGC 101: Guide to User Generated Content Marketing. Available online at: http://www.business2community.com/content-marketing/ugc-101-guide-user-generatedcontent-marketing-0861551 (accessed on 16 October 2017).

Mills, A. (2012) 'Virality in social media: the SPIN framework', Journal of Public Affairs, Vol. 12, No. 2, pp.162-169.

Nielsen (2014) State of the Media: The Social Media Report, 11 September. Available online at: http://www.nielsen.com/us/en/reports/2014/social-media-report-q3 (accessed on 15 June 2015).

Phillips, B.J. and McQuarrie, E.F. (2002) 'The development, change and transformation of rhetorical style in magazine advertisements 1954-1999', Journal of Advertising, Vol. 31, No. 4, pp.1-13.

Phillips, N. and Broderick, A. (2014) 'Has Mumsnet changed me? SNS influence on identity adaptation and consumption', Journal of Marketing Management, Vol. 30, Nos. 9/10, pp.1039-1057.

Prentice, C. and Handsjuk, N. (2016) 'Insights into Vodka consumer attitude and purchasing behaviors', Journal of Retailing and Consumer Services, Vol. 32, pp.7-14.

Pulman-Jones, S. and Strong, C. (2013) 'Visual awareness: a manifesto for market research to engage with the language of images', Market Research Society. Annual Conference Proceedings, No. 1, pp.1-8.

Sabate, F., Berbegal-Mirabent, J., Cañabate, A. and Lebherz, P. (2014) 'Factors influencing popularity of branded content in Facebook fan pages', European Management Journal, Vol. 32, No. 6, pp.1001-1011.

Scott, L.M. and Vargas, P. (2007) 'Writing with pictures: toward a unifying theory of consumer response to images', Journal of Consumer Research, Vol. 34, No. 3, pp.341-356.

Smith, A.N., Fischer, E. and Yongjian, C. (2012) 'How does brand-related user-generated content differ across YouTube, Facebook, and Twitter?' Journal of Interactive Marketing, Vol. 26, pp.102-113.

Smith, T. (2009) 'The social media revolution', International Journal of Market Research, Vol. 51, No. 4, pp.559-561. 